\title{
Prioritizing fodder species based on traditional knowledge: a case study of mithun (Bos frontalis) in Dulongjiang area, Yunnan Province, Southwest China
}

Yanfei Geng ${ }^{1,2,3,4,5}$, Guoxiong Hu$u^{6}$, Sailesh Ranjitkar ${ }^{2,4,7^{*}}$, Yuhua Wang ${ }^{2}$, Dengpan Bu ${ }^{4,5,8}$, Shengji Pei ${ }^{2}$, Xiaokun Ou', Yang $\mathrm{Lu}^{1,2,3}$, Xuelan $\mathrm{Ma}^{2,3}$ and Jianchu $\mathrm{Xu}^{2,7}$

\begin{abstract}
Background: Livestock rearing is one of the oldest and most important types of smallholder farming worldwide. The sustainability of livestock production depends on the efficient utilization of locally available resources. Some traditional methods of raising livestock may offer valuable lessons in this regard. This study documented and evaluated local knowledge of wild forage plants in the Dulongjiang area in Southwest China in the context of rearing mithun (Bos frontalis) in order to provide a sound evidence base for tree fodder selection and the establishment of integrated tree-crop-livestock systems.
\end{abstract}

Methods: The snowball technique was used to identify key informants with specific knowledge about the topic. Free listing and semi-structured interviews were conducted with 58 households. Participatory investigation and transit walks were used to investigate potential fodder species. Ethnobotanical information was collected, documented and organized.

Results: Overall, 142 wild forage plants from 58 families and 117 genera were identified. Species of the Poaceae, Rosaceae and Urticaceae families were most abundant, with 16, 14 and 11 species respectively identified as fodder plants. Our results indicated that tree/shrub forage plays a major role in the diet of mithun, unlike that of other ruminants. Mithun prefers to browse and move around the forest in search of food, particularly rough and even barbed leaves. Tree species like Debregeasia orientalis, Saurauia polyneura and Rubus species were identified as being important fodder sources. Farmers in this area have traditionally relied on common property resources such as community-managed forests and grasslands to feed their livestock. Farmers have strong incentive to raise mithuns rather than other livestock species due to Dulong people's cultural preferences.

Conclusions: The wide variety of plants cited by the informants demonstrate the importance of traditional knowledge in gathering information about forage resources. This diversity also offers the prospect of identifying promising species which could be used as fodder plants. Identifying such species and tree fodder species in particular could help smallholder farmers to integrate trees, livestock and crops as part of a sustainable farming system.

Keywords: Traditional knowledge, Dulong people, Wild fodder plants, Tree fodder, Mithun

\footnotetext{
* Correspondence: sailesh.ranjitkar@gmail.com

${ }^{2}$ Key Laboratory of Economic Plants and Biotechnology, Kunming Institute of

Botany, Chinese Academy of Sciences, Kunming 650201, China

${ }^{4}$ CAAS-ICRAF Joint Lab on Agroforestry and Sustainable Animal Husbandry,

World Agroforestry Centre East and Central Asia, Beijing 100193, China

Full list of author information is available at the end of the article
} 


\section{Background}

Many smallholder farming methods around the world integrate livestock and crop production. Such integration provides draught power for land management and manure for maintaining cropland fertility. In addition, livestock are a critical source of nutrition. China's consumption of meat, and particularly of pork, has increased tremendously as its economy has grown. 50 to $80 \%$ of all pigs produced in China originate from smallholder farms [1,2]. China's rapid economic development and lifestyle transformation have resulted in a growing demand for livestock, and as a result massive restructuring of the livestock sector is underway. New policies and trade agreements have liberalized and industrialized Chinese agriculture, which has enabled enormous increases in production. However, many smallholder farms, which remain a vital part of Chinese rural and indigenous communities, are struggling to survive in the new marketoriented agro-economy [3, 4].

Although economically vulnerable, smallholder systems which integrate crops and livestock continue to be a vital part of agricultural production in China $[1,5]$. Smallholder farmers rely on their observations and experience in feeding and managing their livestock. The sustainable production of livestock usually involves efficient utilisation of locally available resources, particularly feed resources. Understanding the importance of wild forage plants is essential for the efficient utilisation of available forest resources [6, 7]. Exploring the potential for growing such resources in intercropping systems with crops and livestock could help smallholder farmers effectively use their limited land resources. Such integration could mitigate the increasing pressure on land and forest resources generated by growing demand for expansion of agricultural and grazing land $[8,9]$.

Compared to forage grass, tree fodder is particularly important in providing livestock with nutritious food during the dry season when other feed sources are in limited supply [10]. Documenting fodder plants and promoting suitable types of tree fodder for use in home gardens or croplands could be an efficient way to improve sustainable livestock rearing and to change the free grazing style to stall feeding in the mountain without damaging the environment. A combination of traditional and scientific knowledge has been shown to optimize the selection of useful fodder plants [11].

Indigenous people with long histories of livestock rearing may have acquired valuable stores of knowledge about potential fodder/forage resources. Traditional knowledge of fodder plants has been documented in studies of different indigenous groups in several countries, such as Ethiopia, Uganda, Nigeria, India, and Mexico [11-13]. In China, there is an urgent need to document farmers' knowledge of fodder plants and apply it to the design of tree-crop-livestock systems which could improve smallholder farming $[14,15]$. Therefore, this study aims to document local knowledge regarding utilisation and selection of wild forage plants based on indigenous knowledge. The results of this study could be used to provide a shortlist of fodder/forage resources for further nutritional investigation and possible promotion.

\section{Methods}

\section{Study area}

The Dulong ethnic group, also known as Drung, is one of the smallest ethnic groups in China and number only 7000 people. Four thousand of them live in Dulongjiang Township, Gongshan County, Yunnan Province, China (Fig. 1). This township $\left(27^{\circ} 44^{\prime} 9^{\prime \prime} \mathrm{N}, 98^{\circ} 20^{\prime} 59^{\prime \prime} \mathrm{E}\right)$ was the last town in China to be linked by road (Fig. 2). Before 1956, the Dulong people led a relatively isolated life. Slash-and-burn cultivation was practiced on the local mountains until the 1990s, when it was banned by the government. The Dulong language has no script, and the Dulong traditionally made records and transmitted message by means of engraving notches in wood and tying knots [16]. This lack of written records means that local traditional knowledge is particularly vulnerable to being lost and forgotten. There is therefore an urgent need to document the indigenous knowledge associated with this community.

The study area is a typical alpine-gorge area, ranging from an altitude of 3000 to 4000 meters with almost $85 \%$ of the area on steep slopes of more than 25 degrees. The average rainfall is $3672.8 \mathrm{~mm}$ per annum [17]. The area contains 4000 species of higher plants belonging to 280 families and 1068 genera. The Dulong people have an expansive knowledge of the diversity and nutritional potential of the local plants which they use for various purposes. According to elder informants, they have been raising mithun (Bos frontalis) for more than a hundred years. Mithun is a rare semi-domesticated bovine species which is raised mountain areas, mainly for meat, and is distributed only in India, China, Myanmar, Bhutan, Malaysia and Bangladesh [18]. Mithun plays an important role in the economic, social and cultural life of Dulong people. The meat of mithun raised in the traditional way is high in protein $(19.56 \%)$ and low in fat $(0.36 \%)$ [19]. However, this species is vulnerable to extinction according to the International Union for Conservation of Nature and Natural Resources (IUCN) [20].

China's Tui Geng Huan Lin or "Returning Farmland to Forest" (RFFP) program is the world's largest and most successful payment for ecosystem services program. This program is a major contributor to China's dramatic increases in forest cover from perhaps as low as $8 \%$ in 1960 to about $21 \%$ in 2013 [21]. In Dulongjiang area, RFFP compensated rural households for the conversion 

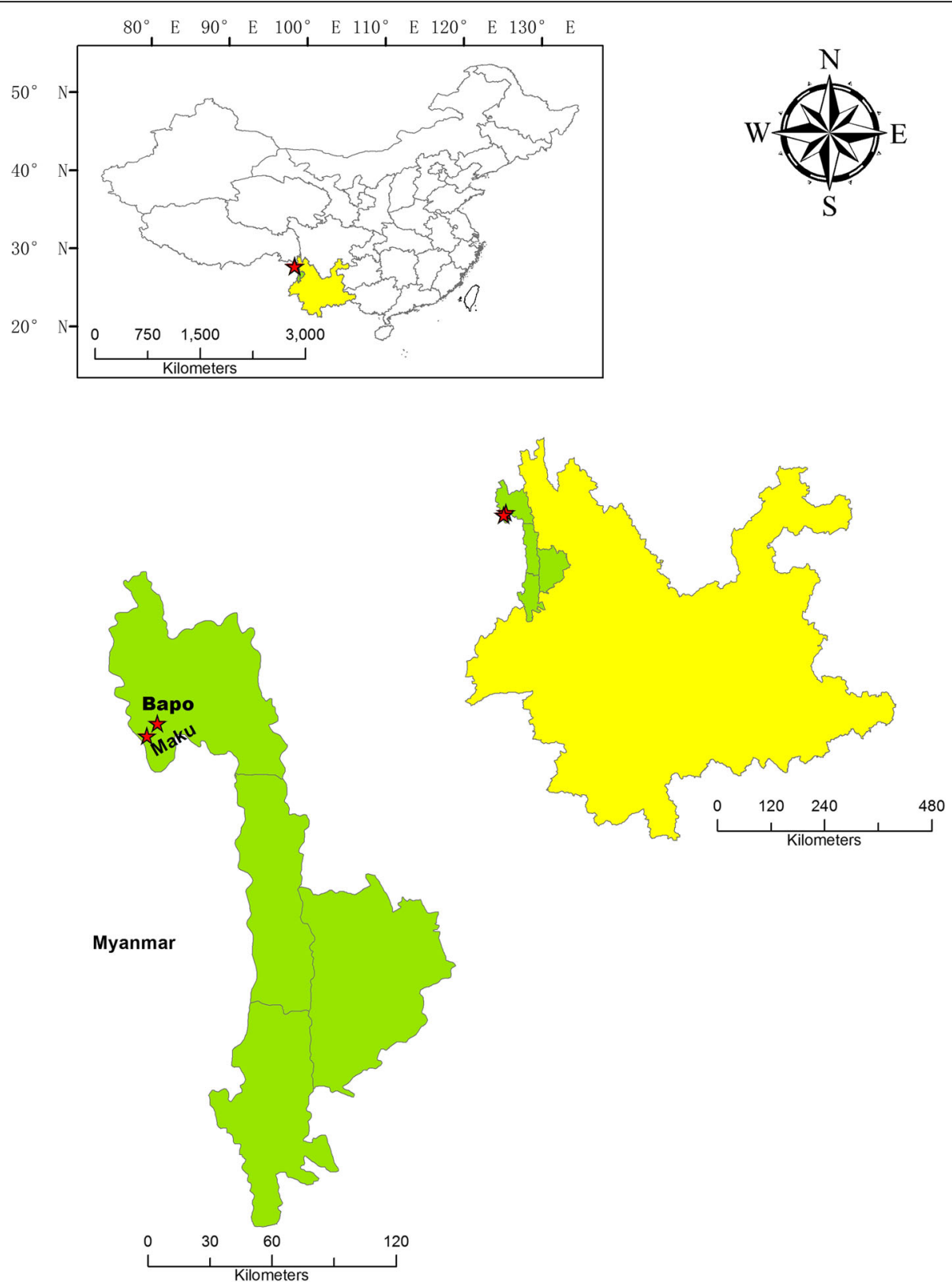

Fig. 1 The study area in Dulongjiang, Gongshan County, Yunnan Province, China

of upland farmland to forestland and financed the afforestation of barren mountainsides. Traditionally, local farmers would employ slash-and-burn cultivation to clear land for grass which would provide the mithun with a fast-growing food source. However, after the government banned slash-and-burn methods in 1990s, the expansion of forests has resulted in a lack of available grassland, which poses a threat to the continued raising of mithun. The use of fodder trees could provide a solution to this problem, but currently inadequate information is available on the forage plants consumed by mithun.
In the present study, we 1) accessed farmers' knowledge of potential forage plants for mithun; 2) documented some potentially useful fodder trees/shrubs; and 3) prioritized important species based on indigenous knowledge. Within this context, the objective of this study is the identification, selection and evaluation of herbaceous and tree species in Dulongjiang area as sources of fodder for mithun.

\section{Data collection}

Our field work revealed that mithun is commonly raised only in Maku(马库), Bapo(巴坡) and Kongdang(孔当) 


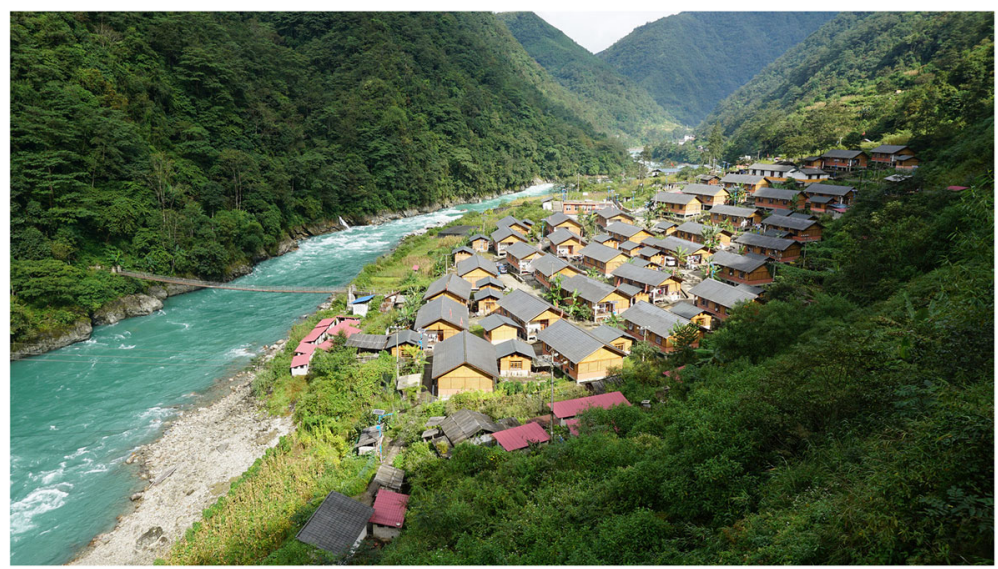

Fig. 2 The landscape of study area

villages, and that there are also a few mithuns in three other villages in the Dulongjiang area. The first two villages are near to Myanmar, which according to our informants is the origin of the local mithun. Our fieldwork was conducted accordingly in $\mathrm{Bapo}$ (巴坡) and Maku(马库) villages (Fig. 1) in 2015 and 2016. Field studies included free lists, semi-structured interviews and participatory investigation. A total of 58 key informants were selected using snowball sampling. The ages of informants ranged from 23 to 71, and the mean age was 45 years old. Because activities related to mithun are generally performed by men, we interviewed only two female informants.

In the first stage of the field research, participants were invited to free list all wild fodder plants favored by mithun. The interviews included the following questions: (1) What plants do mithun eat? (2) What are the mithun's favourite grass and tree fodder sources? (3) What makes mithun grow fast? (4) During the mithun's calving and nursing periods, what plants do they prefer? (5) What habitats do mithun prefer? (6) What are the feeding habits of mithun? (7) What are the main threats to the mithun population? (8) How can we conserve the present population?

In the second stage of the field research, researchers made a transit walk accompanied by local villagers to collect fodder plants and observe mithun browsing in their natural habitat. Nomenclature of all vascular plants follows Flora of China, and the voucher specimens were deposited at the herbarium of the Kunming Institute of Botany, CAS (KUN).

\section{Data analysis}

Ethnobotanical information collected from 58 key informants was documented and organized. Potential fodder species were prioritized according to the consensus reached by informants. Citation frequency (how many times each plant was mentioned by the informants) was used as a measure of consensus. The frequency of citation was the key factor in prioritizing the fodder species, while other ethnobotanical information such as medicinal function, palatability and availability were also considered. Relevant graphical presentations of the documented plants were prepared. Furthermore, the results of our field investigation of fodder plants for mithun were compared with plant lists in the relevant published literature to understand the diet of mithun fully.

\section{Results and discussion \\ Traditional knowledge of wild fodder plants among Dulong people}

Our study revealed that Dulongjiang mithun fed on a highly diverse range of plants. The 58 informants told the interviewers about 142 wild forage plants (Table 1) which belong to 58 families and 117 genera, including 61 species of tree/shrub fodder plants and 81 species of herb forage plants. The arrangement of Angiosperm families is in line with the Angiosperm Phylogeny Website, version 13 (http://www.mobot.org/MOBOT/Research/APweb/welcome.html), and that of ferns follows Christenhusz et al. [22]. Species of the Poaceae, Rosaceae and Urticaceae family were cited most often, with 16, 14 and 11 species respectively (Fig. 3). The wild fodder plants of the Poaceae family included not only various herbs but also tree fodder plants. These were mostly bamboos, and the genus Gaoligongshania, a bamboo, is endemic to this mountain area [23]. Forage plants of the Rosaceae and Urticaceae families were often shrubs and herbs respectively. Shrub forage plants of the Rosaceae family were mostly from the genus Rubus. Forage plants from the Urticaceae family were mostly herbs. In addition to these three families, respondents also mentioned many wild forage plants from the Asteraceae, Lamiaceae, Polygonaceae and Rubiaceae families, indicating a high local diversity of fodder plants. 


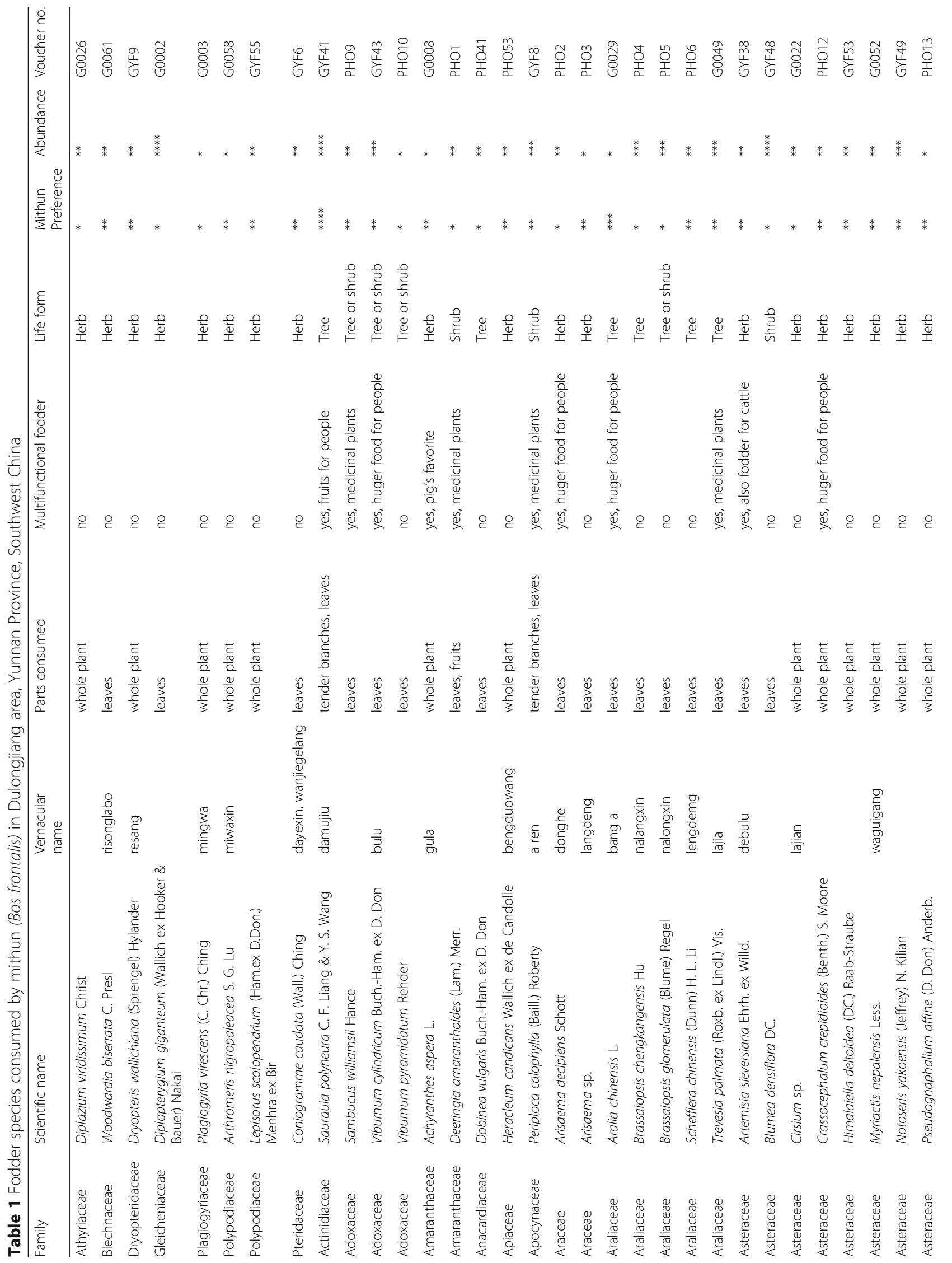




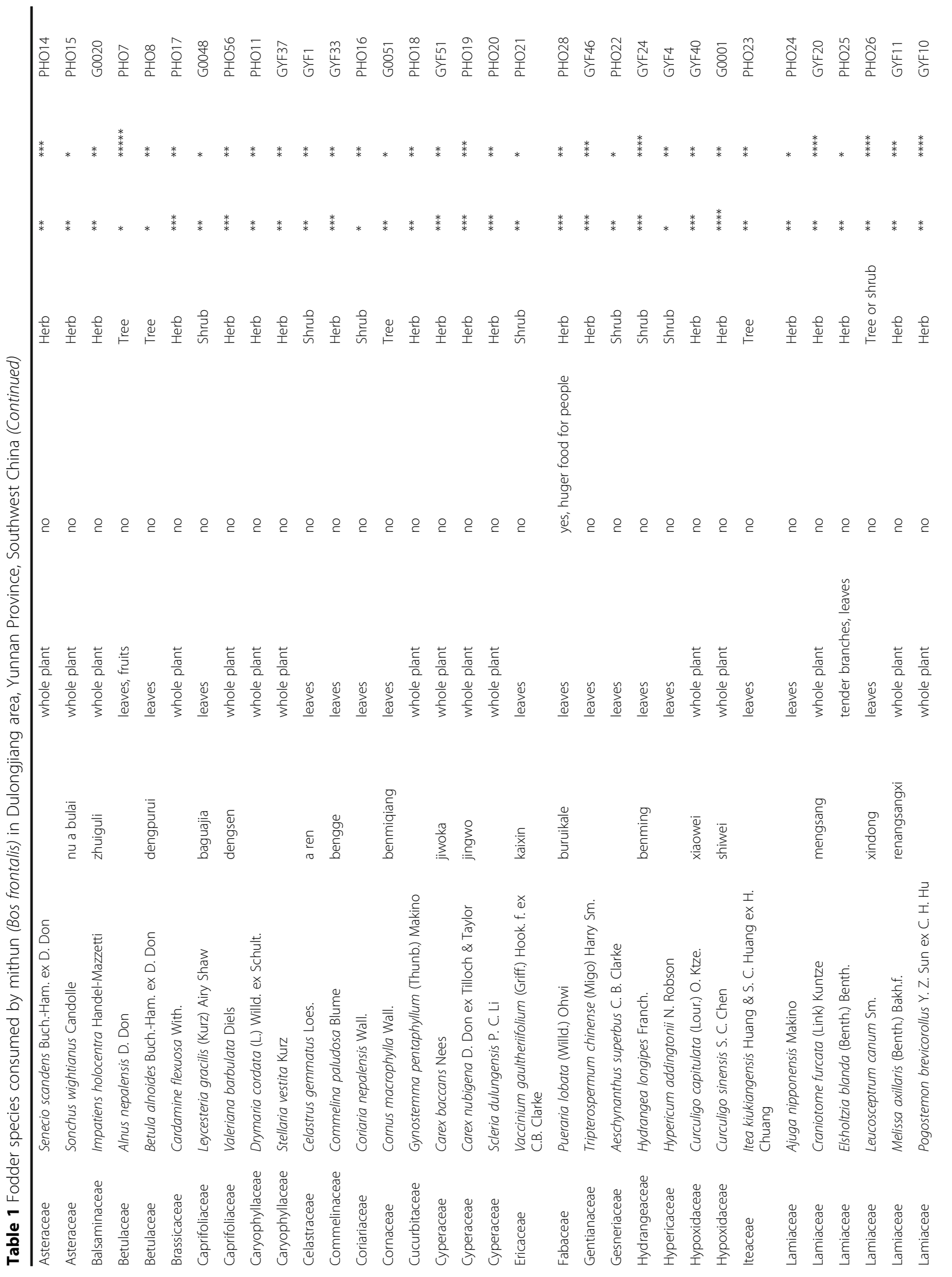




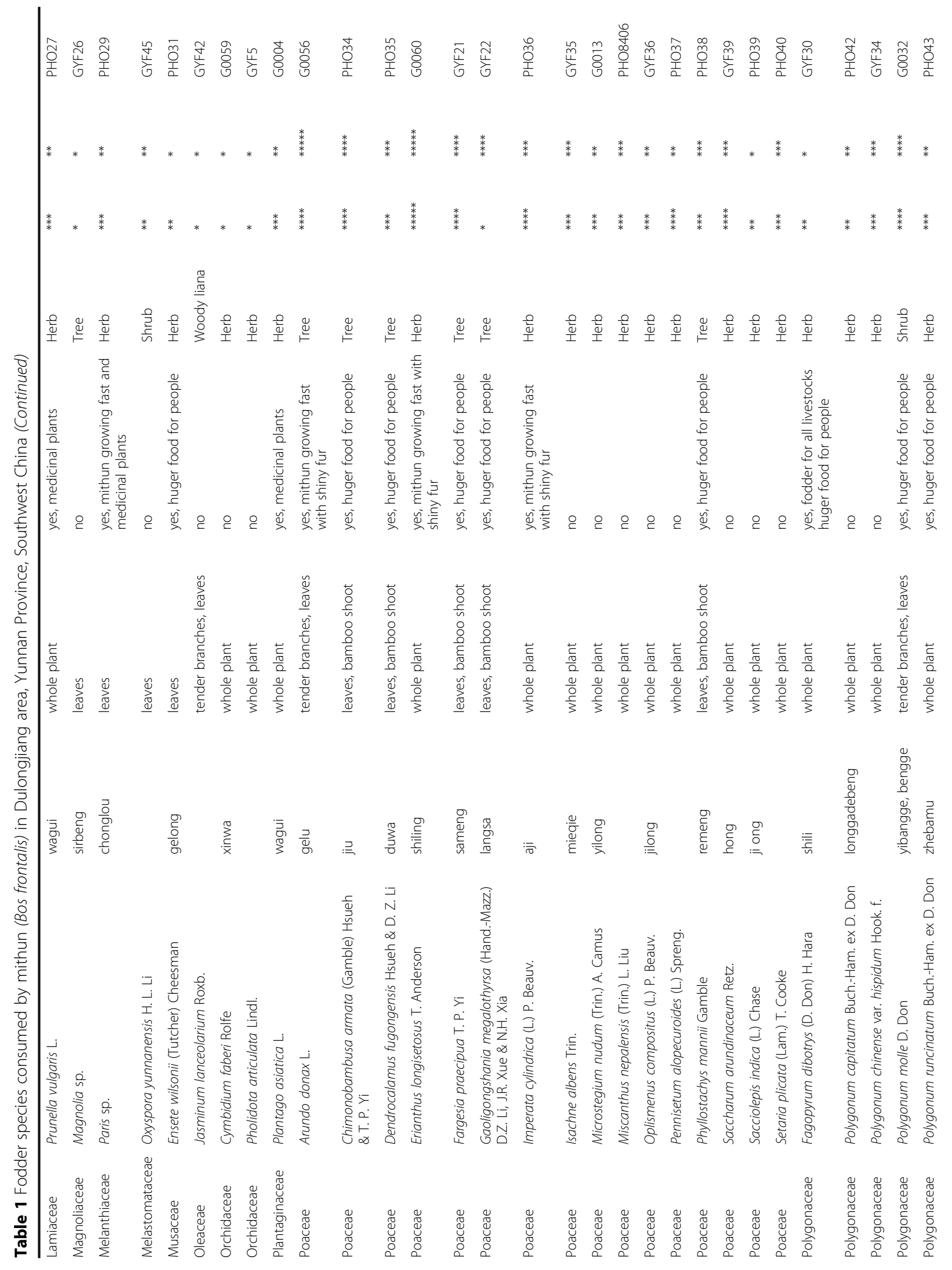




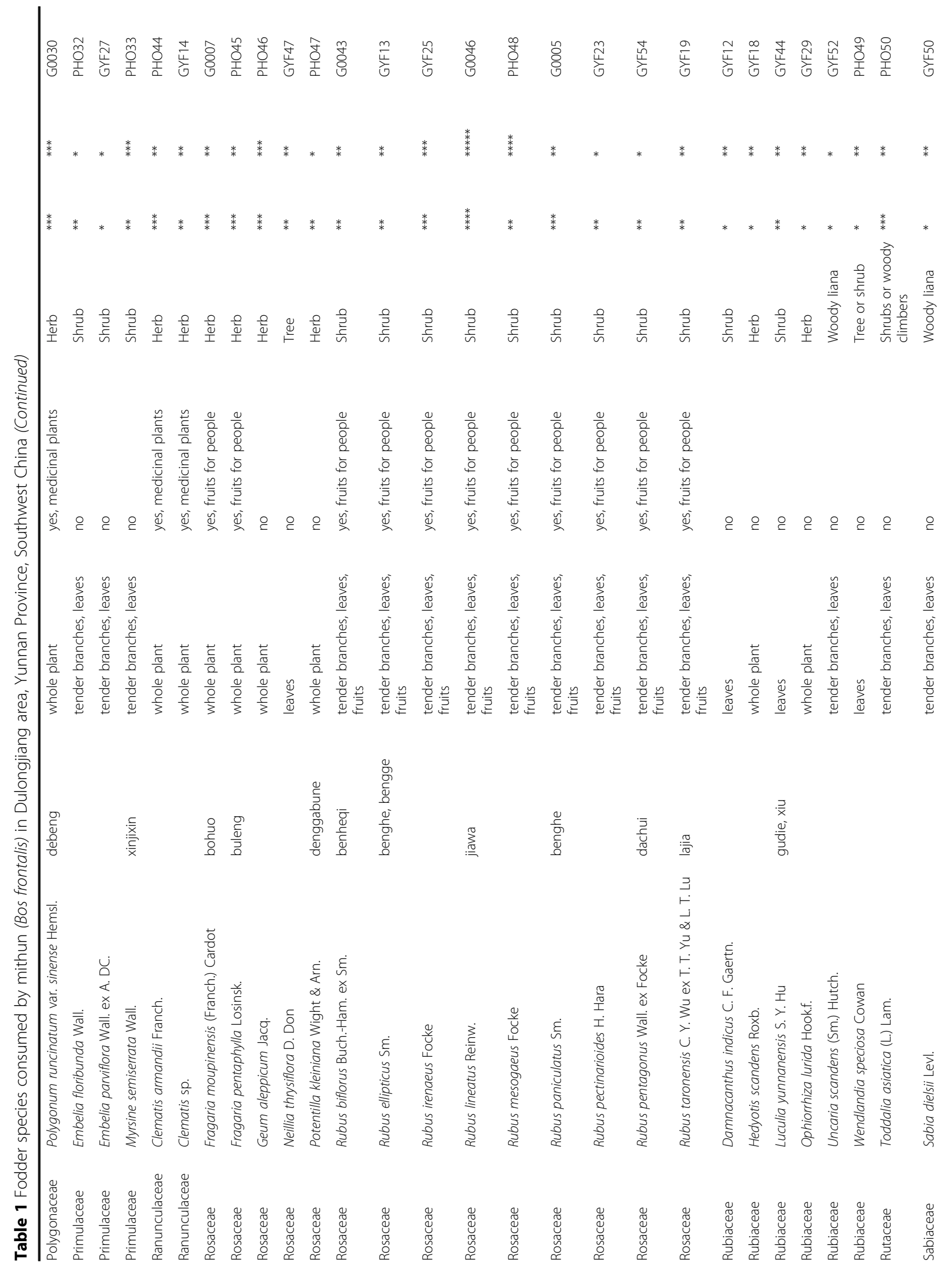




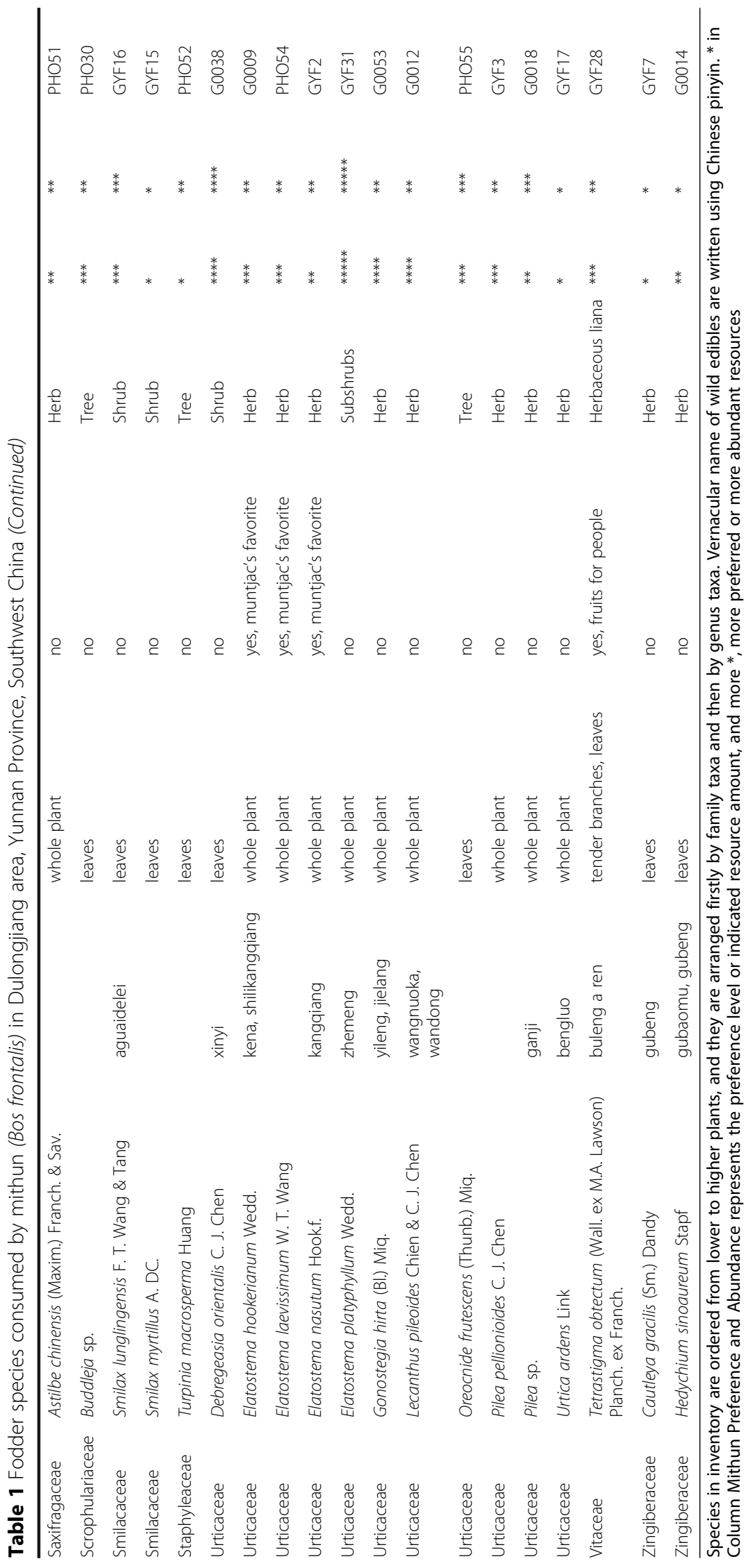




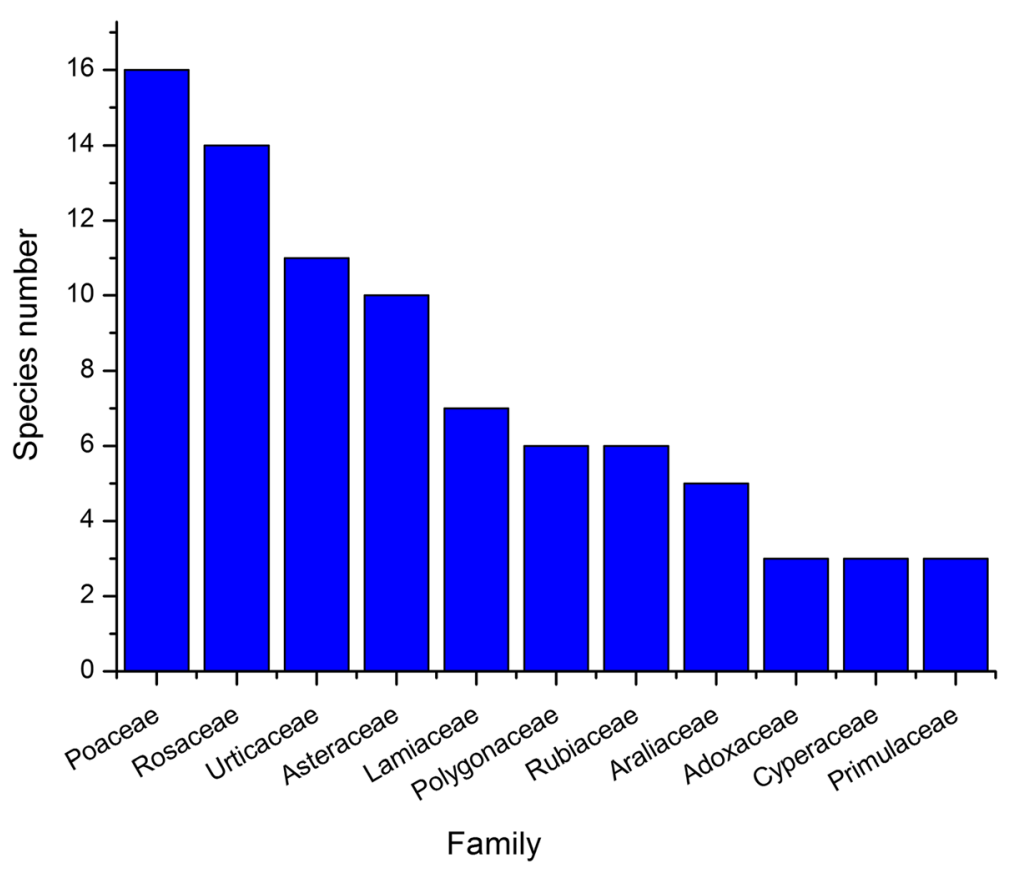

Fig. 3 Frequently cited families of wild fodder plant species

Informants demonstrated a sophisticated knowledge of nutritional characteristics such as nutritional value (fodder plants which enable mithun to grow rapidly), palatability and availability. About $32 \%$ of reported fodders were multifunctional, some of which were said to cause a bodyweight gain and shiny fur. Our informants listed Arundo donax, Paris sp. and Erianthus longisetosus as being very important fodder plants. A. donax is a perennial herbaceous plant and promising energy plant, which could serve as an alternative to wood from shortrotation forestry [24-26]. 50\% of informants claimed that $E$. longisetosus made mithun fur very black and shiny. E. longisetosus is very popular among cattle farmers and was most commonly used in dairy cow feeding $[27,28]$. Paris sp. is a perennial medicinal plant and is a promising candidate for the development of anti-cancer drugs [29-31], and is important forage plant as identified by the informants. Overall, wild forage plants consumed by mithuns were diverse and abundant in the study site. Some studies point out that herbivores have various mechanisms to prevent absorption or reduce the effect of ingested toxins in the wild grazing [32, 33].

The informants reported that mithun preferentially consumed tender leaves (53.52\%). The other parts most frequently consumed were whole plants, tender branches, fruits and bamboo shoots (Fig. 4). Of the plant species cited, $33.8 \%$ had only one part of the plant often eaten by mithun, while the remaining species had more than two

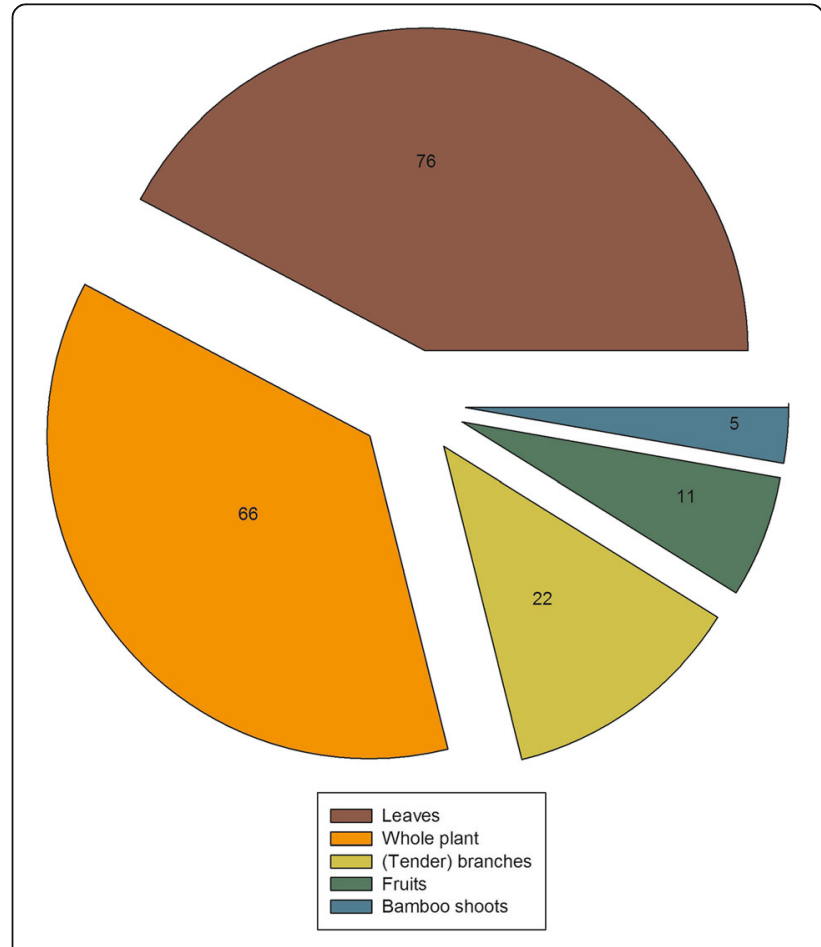

Fig. 4 Plant parts consumed and the number of plant parts used 
parts mentioned as animal feed. Due to the climate of the Dulongjiang area, most wild fodder plants documented in the study can also be accessed in the winter, and there was no significant seasonal difference in the plant species consumed by mithun.

For mithun, less consumed fodder species usually were the less distributed species in Dulongjiang area (Table 1), such as Cymbidium faberi, Pholidota articulate and Urtica ardens. But some common fodder species were less consumed by mithuns in Dulongjiang area probably due to their unpleasant taste, such as Blumea densiflora and Alnus nepalensis.

\section{Feeding habits, prioritizing fodder trees/shrubs and promotion possibilities}

Mithun thrives on jungle forage, tree fodder, shrubs, herbs and other natural vegetation. They stay on the mountain year-round, and farmers do not provide any additional feeding; they merely provide salt three to five times monthly, especially if for some reason it is necessary to restrain the animals from freely ranging around (Fig. 5). Too much salt makes mithun more vulnerable to hypertension, so an adult mithun must be given less than three kilograms of salt per month.

Mithun prefers to move around the forest and browse selectively, particularly on rough or even spiny leaves like those of Debregeasia orientalis, Saurauia polyneura and forage plants in the genus Rubus, such as Rubus lineatus (Fig. 6). Preferred species are often leafy and without lots of stem, with a high leaf table and leaves of low tensile strength [34]. The species found in the diet of the mithun match with the percentage of species found in the botanical composition of the local forest [35]. According to a European study, the ungulates can play a major role as seed dispersers for plant dispersal in forest habitats [36]. However, comparison of this study's results with those of Indian mithun reveals no

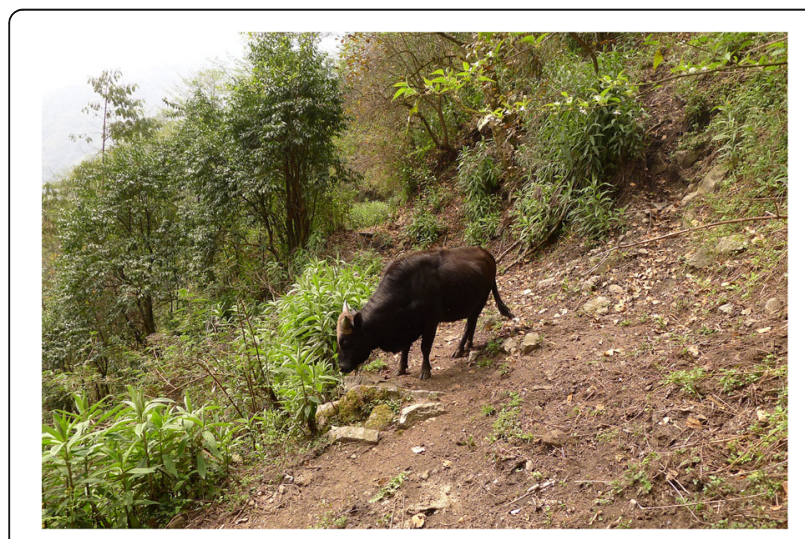

Fig. 5 Foraging mithun in the natural habitat

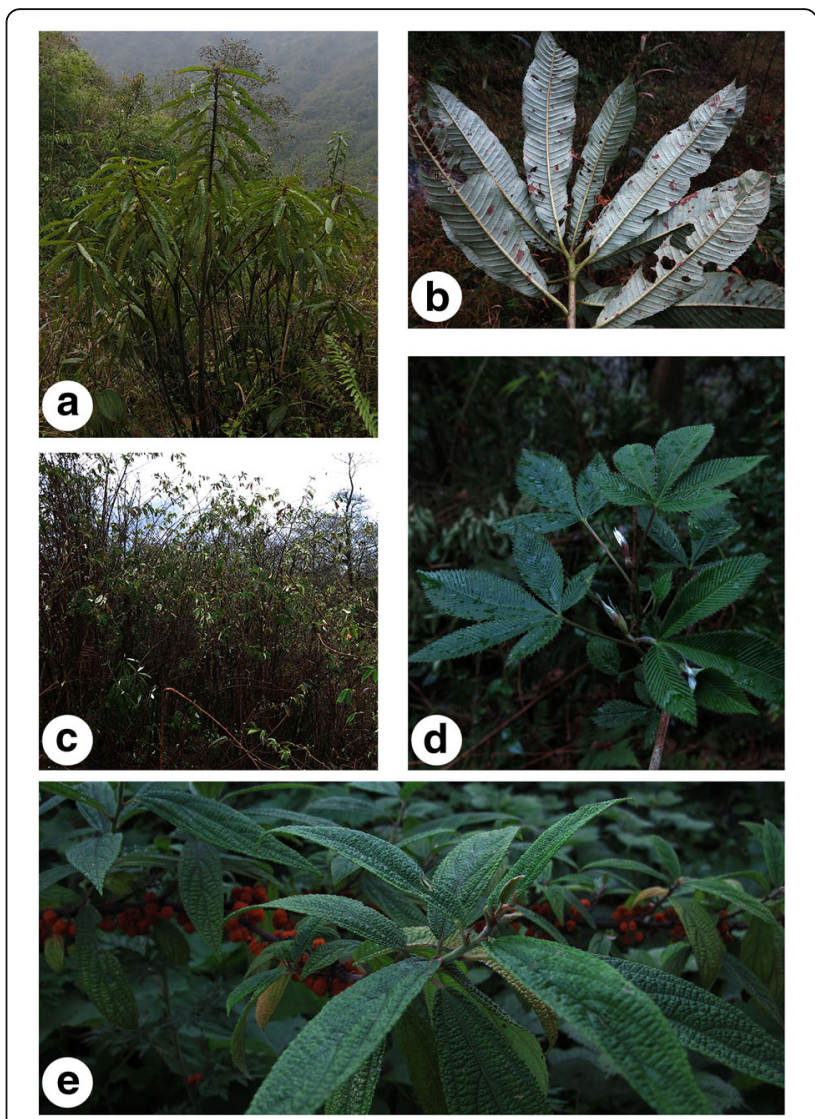

Fig. 6 Three preferred fodder tree species: a-b Saurauia polyneura; c-d Rubus lineatus; e Debregeasia orientalis

overlap between species consumed by mithun in Dulongjiang and in India. This indicates that mithun can adapt well to local environments in which the availability of different foods is limited during some parts of the year [16, 37].

Tree/shrub fodder plays a major role in the diet of mithun, unlike that of other ruminants. In the Dulongjiang area, tree and herb forage plants mostly belong to the Poaceae family, and shrub fodder plants mostly belong to the Rosaceae family. More than half of the 20 most frequently cited fodder species in our survey (frequency 215 ) were trees or shrubs, and half of them belonged to the Poaceae family (Table 2). E. longisetosus and A. donax were abundant in the area, growing on riversides and hillsides at lower elevations. At the onset of winter, the mithun moves to lower elevation regions with higher temperatures and more available food, and these two perennial grasses become their important food source. Bamboo is also preferred by mithun but Dulongjiang has relatively low amounts of bamboo. In interviews, Phyllostachys mannii was mentioned more frequently than the other two (Chimonobambusa armata and Fargesia praecipua) (Table 2). 
Table 2 Frequently cited fodder species consumed by mithun (Bos frontalis) in Dulongjiang area, Yunnan Province, Southwest China

\begin{tabular}{lllll}
\hline Family & Scientific name & Vernacular name & Cited frequency & Life form \\
\hline Poaceae & Erianthus longisetosus T. Anderson & shiling & 47 & Herb \\
Poaceae & Phyllostachys mannii Gamble & remeng & 37 & Tree \\
Poaceae & Imperata cylindrica (L.) P. Beauv. & aji & 31 & Herb \\
Urticaceae & Debregeasia orientalis C. J. Chen & xinyi & 28 & Shrub \\
Poaceae & Arundo donax L. & gelu & 24 & Tree \\
Urticaceae & Elatostema hookerianum Wedd. & kena & 20 & Herb \\
Poaceae & Chimonobambusa armata (Gamble) Hsueh \& T. P. Yi & jiu & 20 & Tree \\
Actinidiaceae & Saurauia polyneura C. F. Liang \& Y. S. Wang & damujiu & 16 & Tree \\
Poaceae & Fargesia praecipua T. P. Yi & sameng & 15 & Tree \\
Rosaceae & Rubus lineatus Reinw. & jiawa & 11 \\
Fabaceae & Pueraria lobata (Willd.) Ohwi & buruikale & 11 \\
Poaceae & Oplismenus compositus (L.) P. Beauv. & jilong & Shrub \\
Polygonaceae & Polygonum molle D. Don & bengge & Herb \\
Polygonaceae & Fagopyrum dibotrys (D. Don) H. Hara & shili & Herb \\
Hydrangeaceae & Hydrangea longipes Franch. & benming & Shrub \\
Poaceae & Saccharum arundinaceum Retz. & hong & Herb \\
Melanthiaceae & Paris sp. & chonglou & Shrub \\
Poaceae & Dendrocalamus fugongensis Hsueh \& D. Z. Li & duwa & 7 \\
\hline
\end{tabular}

This is probably because most of the interviewees seldom go high up into the mountains where the latter two species occur. Imperata cylindrica usually occurs in disturbed place, and it became very common in Dulongjiang when both sides of the valley were converted to farmland. However, the recent reforestation program made it less common. In addition to Poaceae, two species of Urticaceae were also mentioned frequently. $D$. orientalis is often found growing next to streams, while Elatostema hookerianum grows in limited amounts in the forest. S. polyneura and R. lineatus are widely distributed throughout the Dulongiiang area, and were used by a smallholder in Gongshan County to feed mithuns in captivity. Local residents also identified species mentioned above as being able to provide high quality woody fodder. Tree fodder plants often have multipurpose uses. For example, $P$. mannii, $C$. armata and $F$. praecipua yield edible shoots; $R$. lineatus produces edible fruits and planted as a courtyard ornament $[38,39]$; fruits of Saurauia have been important edible fruits since hunger time [40, 41].

The use of fodder trees may also bring other benefits to farmers in Dulongjiang. The sale of tree fodder byproducts by smallholder farmers provides an opportunity to boost household incomes in the study area. Integrating trees into farming practices often has direct effects on crop production such as weed suppression and pest and disease reduction. Livestock such as mithun may also produce higher returns than single crop production as much of the local area is steeply sloped. The use of fodder trees on cropland could be combined with raising mithun and growing crops in integrated tree-crop-livestock systems which would make efficient use of the available land resources without harming natural forests through agricultural extension.

In many countries, fragmentation of land holdings coupled with the declining productivity of public forests motivates farmers to cultivate more trees on their private farmland in order to develop on-farm tree fodder resources [42-44]. However, one of the disadvantages of growing trees on crop land is a negative impact on crop yield. Some species may be suitable for feeding livestock, but agronomically unsuccessful $[45,46]$. Future introductions of fodder plants to new areas and systems may be more successful if based on species and cultivars with long research pedigrees in the same agro-ecologies rather than on unknown species [47], and for which tree-crop interactions have been thoroughly investigated [48].

For many local farming communities, agroforestry is not a new land use practice but a proven production strategy [49]. Our results indicate that this wealth of knowledge can be used to inform the selection of ecologically suitable and economically beneficial fodder trees. These trees could form part of small-scale, mixed tree-crop-livestock systems which could play a major role in improving livelihoods and protecting natural ecosystems in mountain landscapes. 


\section{Mithun farming and livelihoods development}

Crop farming, raising livestock and running small businesses were regarded as the most important economic activities in Dulongjiang area. Livestock, especially mithun and pigs, were in the past raised partly for ceremonial purpose but have now become an important source of income. Farmers in this area and the eastern Himalayas have traditionally relied on common property resources such as forest and grasslands to feed their livestock $[27,50]$. Currently, Dulongjiang farmers use a joint management system whereby a few families take turns to check the numbers and condition of the mithun, and feed them salt.

When asked about the main threats to the mithun population and means of protecting it, almost all local villagers agreed that feeding mithun in stalls would be a better way to avoid accidental death on the steep hillsides as well as from predators such as bears. However, some worried that feeding mithun in this way could make them weak and thin. Mithun still contribute significantly to the livelihoods of traditional smallholders in Dulongjiang area, and both the introduction of new husbandry practices and the planting of specialized forage plants, even in a limited way, present serious challenges. The sale of mithun could boost income, though the ability to do this is often limited by a lack of capital with which to buy calves. According to some studies, mithuns are not usually raised for their milk, but they become accustomed to milking. Mithun produce around $1-1.5 \mathrm{~kg}$ milk/day/animal, and the fat content of their milk varies from 11 to $13 \%$ [18, 28]. If mithun could be more readily sold, farmers would have a stronger incentive to keep mithun, in addition to their cultural value and provision of meat [51]. Farmers also prefer to plant economically and commercially valuable trees over fodder trees [52].

The time invested in raising mithun varied widely among individual households. Members of a household spent about five hours per week feeding their mithuns salt and checking on them. Smallholder livestock production also has the advantage of having lower labor costs than either using hired labor on large-scale farms or the cut-and-carry feeding method employed in other regions [53].

Efforts to improve livestock production in smallholder farming systems face various challenges. First, the selection of different species as candidates for planting fodder trees must take account both their ecological suitability and their potential for supporting local livelihoods [54]. Second, farming systems in this area are usually low input, and under high-risk conditions, farmers are reluctant to invest in improved production technologies $[55,56]$. However, in the Dulongjiang area, the local government has strongly supported under-forest resource development, and has offered each household Amomum tsaoko and Paris sp. seedlings for free. Therefore, the local government could play a vital role in establishing an efficient integrated tree-livestock-crop program and convincing farmers that investing in such systems is worthwhile.

The present study on the forage plants known by Dulong people built upon their locally-developed experience during the process of domestication of the mithun. Attention for the conservation of this rare animal is necessary and proper management of forage source is one of the important aspects in the step of conservation. Ethnobotanical experience from one community can be useful for other community. Similarly, practices and policy in one village could be useful for another village. The concept of integrated tree-livestock-crop can be acceptable and applicable in the regions like northeast India and Myanmar where mithun are naturally distributed [16]. Therefore, the knowledge from Dulongiiang area could be beneficial in the effective management of fodder resources and mithun, and hence it could also contribute to the livelihoods development in the region.

\section{Conclusion}

The results of our research demonstrate the importance of traditional knowledge in identifying suitable tree fodder species. In addition, the diversity of species mentioned by respondents indicates that the study area is rich in forage plants which could be further investigated.

According to the information provided by our informants, fodder species such as Erianthus longisetosus, Arundo donax and Paris sp. may have interesting nutritional properties. However, at present scientific knowledge of these wild fodder species is too sparse to support the promotion of fodder trees at the farm level. Padmakumar et al. had listed nutritional value of some species closely related to our findings. This lead to the Ffurther research into these and other frequently-cited species which could help farmers select fodder trees which are ecologically suitable and economically beneficial [57]. Tree fodder species such as Debregeasia orientalis and Saurauia polyneura were highlighted by local farmers, as well as forage plants in the genus Rubus. Further studies are needed including a nutritional evaluation of various fodder species consumed by mithun and researches into the effects of different fodder species on rumen microbial flora and environment of mithun.

\section{Acknowledgments}

Special gratitude is expressed to the families of Shirong Wang for their kind hospitality, and to the Zhijun Wang, Wenzhe Li and Tianzhu Long for their genuine assistance. We are also thankful for the help of Dr. Yuxiao Zhang, Dr. Liang Zhang, Prof. Heng Li and Prof. Hua Peng with botanical identification and Andrew Stevenson for English editing. 


\section{Funding}

This research was funded by the CAAS project "The Agricultural Science and Technology Innovation Program (ASTIP-IAS07)". We also acknowledge support from CGIAR research programs on 'Forests, Trees and Agroforestry' (CRP6.2).

\section{Availability of data and materials}

All datasets on which the conclusions of the paper rely made available in the manuscript.

\section{Authors' contributions}

YFG, SR and JCX conceived and designed the research. YFG,GXH,YL and XLM collected the data, and GXH provided the botanical identification. XKO, YHW and SJP gave advice on interviews. YFG analyzed the data and prepared the manuscript. SR and DPB reviewed the manuscript. All authors read and approved the final manuscript.

\section{Competing interests}

The authors declare that they have no competing interests.

\section{Consent for publication}

The people interviewed were informed about the study's objectives and the eventual publication of the information gathered, and they were assured that the informants' identities would remain undisclosed.

\section{Ethics approval and consent to participate}

The authors asked for permission from the local authorities and the people interviewed to carry out the study.

\section{Publisher's Note}

Springer Nature remains neutral with regard to jurisdictional claims in published maps and institutional affiliations.

\section{Author details}

${ }^{1}$ Institute of Ecology and Geobotany, Yunnan University, Kunming 650091, China. ${ }^{2}$ Key Laboratory of Economic Plants and Biotechnology, Kunming Institute of Botany, Chinese Academy of Sciences, Kunming 650201, China. ${ }^{3}$ University of Chinese Academy of Sciences, Beijing 100049, China. ${ }^{4}$ CAAS-ICRAF Joint Lab on Agroforestry and Sustainable Animal Husbandry, World Agroforestry Centre East and Central Asia, Beijing 100193, China. ${ }^{5}$ State Key Laboratory of Animal Nutrition, Institute of Animal Science, Chinese Academy of Agricultural Sciences, Beijing 100193, China. ${ }^{6}$ College of Life Sciences, Guizhou University, Guiyang 550025, China. ${ }^{7}$ World Agroforestry Centre East and Central Asia, Kunming 650201, China. ${ }^{8}$ Hunan Co-Innovation Center of Animal Production Safety, CICAPS, Changsha 410128, China.

\section{Received: 9 December 2016 Accepted: 17 April 2017}

Published online: 04 May 2017

\section{References}

1. Riedel S, Schiborra A, Huelsebusch C, Huanming M, Schlecht E. Opportunities and challenges for smallholder pig production systems in a mountainous region of Xishuangbanna, Yunnan Province, China. Trop Anim Health Prod. 2012:44(8):1971-80.

2. Neo H, Chen L. Household income diversification and the production of local meat: The prospect of small-scale pig farming in southern Yunnan, China. Area. 2009;41(3):300-9.

3. Tilt B. The struggle for sustainability in rural China: Environmental values and civil society. New York: Columbia University Press; 2013.

4. Schneider M. Feeding China's pigs: Implications for the environment, China's smallholder farmers and food security. Minneapolis: Institute for Agriculture and Trade Policy; 2011.

5. Fu Y, Guo H, Chen A, Cui J. Household differentiation and on-farm conservation of biodiversity by indigenous households in Xishuangbanna, China. Biodivers Conserv. 2006:15(8):2687-703.

6. Sansoucy R. Livestock-a driving force for food security and sustainable development. World. 1995:3074(5389):1035.

7. Nelson HE. Challenges of documenting and disseminating agricultural indigenous knowledge for sustainable food security in Soroti District. Kampala: Makerere University; 2015.
8. Weindl I, Lotze-Campen H, Popp A, Müller C, Havlík P, Herrero M, Schmitz C, Rolinski S. Livestock in a changing climate: Production system transitions as an adaptation strategy for agriculture. Environ Res Lett. 2015;10(9):094021.

9. Erb K-H, Lauk C, Kastner T, Mayer A, Theurl MC, Haberl H. Exploring the biophysical option space for feeding the world without deforestation. Nat Commun. 2016:7:11382

10. Panday K. Fodder trees and tree fodder in Nepal. Berne: Swiss Development Cooperation; 1982

11. Nunes AT, Lucena RFP, dos Santos MVF, Albuquerque UP. Local knowledge about fodder plants in the semi-arid region of northeastern Brazil. J Ethnobiol Ethnomed. 2015;11(1):1.

12. Okoli I, Ebere C, Uchegbu M, Udah C, Ibeawuchi I. A survey of the diversity of plants utilized for small ruminant feeding in south-eastern Nigeria. Agric Ecosyst Environ. 2003;96(1):147-54.

13. Nahed J, Villafuerte L, Grande D, Pérez-Gil F, Alemán T, Carmona J. Fodder shrub and tree species in the highlands of southern Mexico. Anim Feed Sci Technol. 1997;68(3):213-23.

14. Stur W, Ibrahim T, Tuhulele M, Binh LH, Gabunada F, Nakamanee I, Phimphachanhvongsod V, Liu G, Horne P. Adaptation of forages to climate, soils and use in smallholder farming systems in Southeast Asia. In: Aciar Proceedings. Bruce: ACIAR; 2000.

15. Altieri MA, Funes-Monzote FR, Petersen P. Agroecologically efficient agricultural systems for smallholder farmers: Contributions to food sovereignty. Agron Sustain Dev. 2012;32(1):1-13.

16. Das KC, Prakash B, Rajkhowa C. Nutrition and feeding of mithun (Bos frontalis) in hill livestock farming system. Indian J Anim Nutr. 2008;25:1-10.

17. Feng J, Wang $X$, Fang J. Altitudinal pattern of species richness and test of the rapoport's rules in the drung river area, southwest China. Acta Sci Nat Univ Pekin. 2006;42(4):515-20.

18. Moyong O. Commoditisation and sustainable management of mithun (Bos frontalis) in Arunachal Pradesh, North-east India. J Agric Vet Sci. 2012;1(3): $39-43$.

19. Ge C, Yuan X, Chen T. A study on slaughtering performance of Yunnan zebu and width forehead cattle (Bos frontalis). J Yellow Cattle Sci. 1996:3:42-4.

20. IUCN. Red list of threatened species. 2002. cited 2016.

21. Trac CJ, Schmidt AH, Harrell S, Hinckley TM. Environmental reviews and case studies: Is the returning farmland to forest program a success? Three case studies from Sichuan. Environ Pract. 2013;15(3):350-66.

22. Christenhusz M, Zhang X, Schneider $H$. A linear sequence of extant families and genera of lycophytes and ferns. Phytotaxa. 2011;19(1):7-54.

23. Li R, Dao Z, Li H. Seed plant species diversity and conservation in the northern Gaoligong Mountains in Western Yunnan, China. Mt Res Dev. 2011;31(2):160-5.

24. Neto CP, Seca A, Nunes A, Coimbra M, Domingues F, Evtuguin D, Silvestre A, Cavaleiro J. Variations in chemical composition and structure of macromolecular components in different morphological regions and maturity stages of Arundo donax. Ind Crop Prod. 1997;6(1):51-8.

25. Faix $O$, Meier $D$, Beinhoff $O$. Analysis of lignocelluloses and lignins from Arundo donax L. and Miscanthus sinensis Anderss., and hydroliquefaction of Miscanthus. Biomass. 1989;18(2):109-26.

26. Styles D, Jones MB. Energy crops in Ireland: Quantifying the potential lifecycle greenhouse gas reductions of energy-crop electricity. Biomass Bioenergy. 2007;31(11):759-72.

27. Kumaresan A, Prabhakaran P, Bujarbaruah K, Pathak K, Chhetri B, Ahmed S. Reproductive performance of crossbred dairy cows reared under traditional low input production system in the eastern Himalayas. Trop Anim Health Prod. 2009:41(1):71-8.

28. Yadav B, Verma N. Studies on feed utilization growth pattern and milk composition in mithun (Bos frontalis). Anim Genet Resour Inf. 1996:20:9-15.

29. Zhang T, Liu H, Liu X, Xu D, Chen X, Wang Q. Qualitative and quantitative analysis of steroidal saponins in crude extracts from Paris polyphylla var. yunnanensis and $P$. polyphylla var. chinensis by high performance liquid chromatography coupled with mass spectrometry. J Pharm Biomed Anal. 2010:51(1):114-24.

30. Yan L, Zhang Y, Gao W, Man S, Wang Y. In vitro and in vivo anticancer activity of steroid saponins of Paris polyphylla var. yunnanensis. Exp Oncol. 2009;31(1):27-32.

31. Man S, Gao W, Zhang Y, Jin X, Ma C, Huang X, Li Q. Characterization of steroidal saponins in saponin extract from Paris polyphylla by liquid chromatography tandem multi-stage mass spectrometry. Anal Bioanal Chem. 2009;395(2):495-505. 
32. Provenza FD, Villalba JJ, Dziba L, Atwood SB, Banner RE. Linking herbivore experience, varied diets, and plant biochemical diversity. Small Rumin Res. 2003:49(3):257-74.

33. Rogosic J. The role of secondary compounds in foraging on Mediterranean rangelands. In new trends for innovation in the Mediterranean animal production. Wageningen: Wageningen Academic Publishers; 2012.

34. Meissner $\mathrm{H}$. Recent research on forage utilization by ruminant livestock in South Africa. Anim Feed Sci Technol. 1997;69(1):103-19.

35. Li R, Dao Z, Ji Y, Li H. A floristic study on the seed plants of the northern Gaoligong Mountains in Western Yunnan, China. Plant Diversity. 2003;29(6): $601-15$

36. Jaroszewicz B, Pirożnikow E, Sondej I. Endozoochory by the guild of ungulates in Europe's primeval forest. For Ecol Manag. 2013;305:21-8,

37. Prakash B, Dhali A, Rathore S, Das K, Walling I, Vupru K, Mech A, Baruah K, Rajkhowa C. Chemical composition and nutritional evaluation of various foliages consumed by mithun (Bos frontalis). Anim Feed Sci Technol. 2009; 150(3):223-9.

38. Angami A, Gajurel P, Rethy P, Singh B, Kalita S. Status and potential of wild edible plants of Arunachal Pradesh. Indian J Tradit Knowl. 2006;5(4):541-50

39. Naruhashi N, Nepalese Rubus. V International Symposium on Rubus and Ribes 262. 1989.

40. Dao Z, Long C, Liu Y. Preliminary study on plants used by Nu people in Gaoligongshan area, Yunnan. Biodivers Sci. 2003;11(3):231-9.

41. Long C, Li H, Zhou Y, Dao Z, Taku A. Ethnobotanical studies in Gaoligong mountains: The dulong ethnic group. Plant Diversity. 1999;(Suppl. XI):137-44.

42. Carter AS, Gilmour DA. Increase in tree cover on private farm land in central Nepal. Mt Res Dev. 1989;19(4):381-91.

43. Gilmour DA, Nurse M. Farmer initiatives in increasing tree cover in Central Nepal. Mt Res Dev. 1991;11(4):329-37.

44. Subba K. A comparative study of land use changes in Dhankuta District between 1978-1990, in Koshi Hills Development Programme. Nepal: Dhankuta; 1992.

45. Wilson A. The digestibility and voluntary intake of the leaves of trees and shrubs by sheep and goats. Crop Pasture Sci. 1977;28(3):501-8.

46. Reed J, Soller H, Woodward A. Fodder tree and straw diets for sheep: Intake, growth, digestibility and the effects of phenolics on nitrogen utilisation. Anim Feed Sci Technol. 1990:30(1):39-50.

47. Lenne J, Wood D. Is there a 'logic of fodder legumes' in africa? Food Policy. 2004;29(5):565-85.

48. Thapa B, Sinclair FL, Walker D. Incorporation of indigenous knowledge and perspectives in agroforestry development. Agrofor Syst. 1995;30(1-2):249-61.

49. Rusten EP, Gold MA. Understanding an indigenous knowledge system for tree fodder via a multi-method on-farm research approach. Agrofor Syst. 1991;15(2-3):139-65.

50. Singh V, Tulachan PM, Partap T. Livestock feeding management at smallholder dairy farms in Uttaranchal hills. Indian J Anim Sci. 2001;71(12):1172-7.

51. Tulachan PM, Neupane A. Livestock in mixed farming systems of the Hindu Kush-Himalayas. Rome: FAO; 1999.

52. Yang H. Land conservation campaign in China: Integrated management, local participation and food supply option. Geoforum. 2004:35(4):507-18

53. Herold P, Markemann A, Zárate AV. Resource use, cattle performance and output patterns on different farm types in a mountainous province of northern Vietnam. Anim Prod Sci. 2011;51(7):650-61.

54. Weyerhaeuser H, Wilkes A, Kahrl F. Local impacts and responses to regional forest conservation and rehabilitation programs in China's northwest Yunnan Province. Agric Syst. 2005;85(3):234-53

55. Scoones I. Coping with drought: Responses of herders and livestock in contrasting savanna environments in Southern Zimbabwe. Hum Ecol. 1992; 20(3):293-314

56. Nkomboni D, Sisito G, van Rooyen A, Tui SH-K, Sikosana J, Ndlovu L. The potential for increasing cattle productivity in mixed farming systems of Zimbabwe. Livest Res Rural Dev. 2014;26(6):111.

57. Padmakumar V, Haque N, Sirie R, Khate K, Deka R, Rutsa V, Solomon K. Availability and nutritional value of wild forages as feed for pigs and mithun in Nagaland, India, ILRI Project Report. Nairobi: ILRI; 2015.

\section{Submit your next manuscript to BioMed Central and we will help you at every step:}

- We accept pre-submission inquiries

- Our selector tool helps you to find the most relevant journal

- We provide round the clock customer support

- Convenient online submission

- Thorough peer review

- Inclusion in PubMed and all major indexing services

- Maximum visibility for your research

Submit your manuscript at www.biomedcentral.com/submit
Biomed Central 